J. Venom. Anim. Toxins incl. Trop. Dis.

V.12, n.4, p.659, 2006.

Thesis.

ISSN 1678-9199.

\title{
TELE-EDUCATION ENVIRONMENT AND DIDACTIC ICONOGRAPHY IN SEXUAL TRANSMITTED DISEASES
}

Thesis: Ferreira ASSBS. submitted this dissertation for her Masters in Science at the School of Medicine, São Paulo University, USP, São Paulo, Brazil, 2005.

Advisor: Dr. Chao Lung Wen

ABSTRACT: The field of advertising has developed techniques of mass communication and rapid transmission of information. Among these techniques are slogans and iconographies. This work used such tools for educational purposes and was divided into three modules. Module 1 evaluated the use of simplified textual communication (slogans) about the subject "Sexually Transmitted Diseases". It was applied to third-year medical students, which had not taken the course on this theme. To evaluate the impact of the textual communication form (slogans), long phrases were elaborated in scientific language containing 15 topics. From these long phrases, compact phrases were developed using techniques of the advertising area for elaboration of slogans. Three forms of didactic material about that theme were developed. The first form consisted of long phrases in descriptive topics, using scientific language. The second was constituted exclusively of compact phrases in the form of slogans, and the third was composed of the combination of the two previous forms. Then, 10 multiple-choice questions were elaborated and applied in two phases. In the first phase, application occurred immediately after the reading of didactic texts; in the second phase, it happened 60 days after the reading. For statistical analysis, Snedcor's $\mathrm{F}$ test was used for analysis of variance, at $5 \%$ significance level. There was an increase in memorization by students who read the material containing the association between long phrases and slogans, which indicates that the latter, when used as an auxiliary model of learning, can bring significant benefits for education. Module 2 consisted of analyzing the elaboration of educational videos produced in graphic computing (called iconographies) for development of dynamic communication means. The theme "Hair Cycle" was utilized. Viability of high quantities of information in few minutes of animation could be demonstrated together with the advantage of presenting the process in a dynamic form without wasting scientific details. Module 3 presented the inclusion of slogans in educational videos produced in graphic computing about the "Hair Cycle", showing a new tool for rapid and efficient transference of data. Slogans and iconographies, when utilized in educational material, can bring significant benefits for the student's learning.

KEY WORDS: advertising/methods, three-dimensional imaging, instruction.

CORRESPONDENCE TO:

ANA SILVIA S. B. S. FERREIRA, Departamento de Doenças Tropicais e Diagnóstico por Imagem, Faculdade de Medicina de Botucatu, UNESP, Distrito de Rubião Junior, s/n, 18618-000, Botucatu, SP, Brasil. Phone: 551438116212. Email: anasilvia@cevap.org.br 